УДК 372.854:378

ХИМИЧЕСКАЯ ПОДГОТОВКА В ПАРАМЕТРАХ РАЗВИТИЯ ИНТЕЛЛЕКТУАЛЬНОЙ КУЛЬТУРЫ УЧАЩИХСЯ В ШКОЛЕ И ВУЗЕ

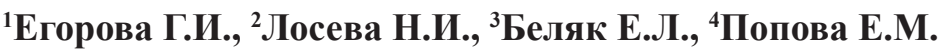

${ }^{1}$ ФББОУ ВО «Тюменский индустриальный университет», Тюмень, е-таil: egorovagi@list.ru; ${ }^{2}$ Филиал ФГБОУ ВО «Тюменский индустриальный университет», Тобольск, е-таil: Ini99@yandex.ru; ${ }^{3}$ МАОУ СОШ № 16 имени В.П. Неймышева, Тобольск, e-mail: elenabelyak@yandex.ru; ${ }^{4}$ МАОУ СОШ № 20, Тобольск, e-mail: pem1015@yandex.ru

\begin{abstract}
В статье рассматривается новое социокультурное видение химической подготовки с учетом развития интеллектуальной культуры учащихся с различных позиций. Во-первых, показаны проблемы и перспективы химической подготовки в системе взаимодействия школа - вуз - предприятие, показана ключевая роль химических знаний в развитии и формировании научной картины мира для школьников, студентов. Вовторых, раскрыто функциональное значение, методологические подходы, приоритетные роли химической подготовки в развитии российского общества, научные идеи выдающихся ученых, методистов, практиков, реализуемые в ходе химической подготовки. С этих позиций показано значение химической подготовки как важного условия качественной жизнедеятельности любого человека в глобальном мире. В-третьих, проведено сравнение действующих систем методического характера (содержательный аспект, деятельностный аспект) с учетом параметров развития интеллектуальной культуры как части общей культуры личности. Выявлено педагогическое осмысление роли интеллектуальной культуры как важного условия повышения качества химической подготовки будущих бакалавров, специалистов в вузе. Внимание фокусируется на возможностях реализации системы химической подготовки с учетом приемов, методов развития интеллекта, мыслительных способностей, интеллектуальной культуры с целью подготовки дипломированного специалиста, бакалавра, соответствующих современным требованиям промышленного предприятия.
\end{abstract}

Ключевые слова: химическая подготовка, интеллектуальная культура, профессиональная компетентность, качество подготовки

\title{
CHEMICAL PREPARATION IN THE PARAMETERS OF THE DEVELOPMENT OF INTELLECTUAL CULTURE OF STUDENTS IN SCHOOL AND UNIVERSITY
}

${ }^{1}$ Egorova G.I., ${ }^{2}$ Loseva N.I., ${ }^{3}$ Belyak E.L., ${ }^{4}$ Popova E.M.

${ }^{1}$ Tyumen Industrial University, Tyumen, e-mail: egorovagi@list.ru;

${ }^{2}$ Tyumen Industrial University, branch in Tobolsk, e-mail: Ini99@yandex.ru;

${ }^{3}$ Municipal Autonomous educational institution Secondary School № 16 named after V.P. Neymyshev,

Tobolsk,e-mail: elenabelyak@yandex.ru;

${ }^{4}$ Municipal Autonomous educational institution Secondary School № 20, Tobolsk, e-mail: pem1015@yandex.ru

\begin{abstract}
The article considers a new socio-cultural vision of chemical training, taking into account the development of intellectual culture of students from various positions. First, it shows the problems and prospects of chemical training in the system of interaction «school-University - enterprise», shows the key role of chemical knowledge in the development and formation of a scientific picture of the world for schoolchildren and students. Secondly, the functional significance, methodological approaches, priority roles of chemical training in the development of Russian society, scientific ideas of outstanding scientists, methodologists, and practitioners implemented in the course of chemical training are revealed. From these positions, the importance of chemical preparation as an important condition for the quality of life of any person in the global world is shown. Third, a comparison of existing systems of a methodological nature (content aspect, activity aspect), taking into account the parameters of the development of intellectual culture as part of the General culture of the individual. Pedagogical understanding of the role of intellectual culture as an important condition for improving the quality of chemical training of future bachelors and specialists in higher education is revealed. Attention is focused on the possibilities of implementing a system of chemical training, taking into account the techniques, methods of developing intelligence, thinking abilities, intellectual culture in order to prepare a certified specialist, bachelor, corresponding to the modern requirements of an industrial enterprise.
\end{abstract}

Keywords: chemical training, intellectual culture, professional competence, quality of training

История становления Российского государства всегда была связана с оригинальными идеями инженерной химической мысли, ориентированными на накопление, преобразование старых химических материалов и создание новых (полимеры, лаки, краски, лекарство и т.д.), а также инновационных технологий, что обеспечивало прогресс России на мировом рынке. Здесь уместно вспомнить выдающихся ученых-технологов и их достижения: первые краски (Н. Зинин, 1844 г.), первый отечественный полимер (С. Лебедев, 1932 г.), первый отечественный антибиотик (3. Ермольева, 1942 г.), первый пластик (Г. Петров, 1914 г.). Открытия настолько велики, что требуют отдельной систематики и научного исследования. Многие отечественные достижения ученых 
химиков-технологов, в целом достижения химической науки лежали в основе процветания современной цивилизации.

Глобальность перемен в социуме, в государстве связана с новыми открытиями, научными достижениями, создание и осмысление которых невозможно без участия компетентного, интеллектуально грамотного инженера химического профиля.

Переход на интеллектуальный тип профессиональной химической подготовки, основанной на химических знаниях, мыслительных операциях, умениях, обеспечит компетентность и профессионализм выпускника. Однако сложилось некоторое противоречие между высокими требованиями ФГОС новых поколений и низким уровнем химической подготовки, химической грамотности будущих бакалавров, специалистов, что недопустимо в современных условиях развития государства, так как наши выпускники должны вливаться в коллектив промышленных предприятий и общества в целом [1].

Выделим совокупность значимых проявлений актуальности химической подготовки. Первое проявление связываем со значением химических знаний и их приоритетной роли для развития топливно-энергетической отрасли (ТЭК), нефте-, газохимии, коммуникаций, производства материалов. Второе проявление более высокого порядка связываем с развитием химии материалов на основе природных, синтетических сырьевых ресурсов (синтез каучуков, лекарств, мономеров, полимерных композиций). Третье проявление связываем с разработкой инновационных методов получения новых химических веществ, что ориентировано на современное развитие любого государства. Четвертое проявление связываем с безопасностью. Химическая подготовка как стратегическая отрасль лежит в основе всех сфер деятельности человека, создает среду экологической безопасности для каждого человека. Здесь уместно говорить о химической компетентности, в основе которой лежат системные химические знания, раскрывающие закономерности окружающего мира, что обеспечивает принятие правильных решений производственного, экологического, социокультурного характера.

На наш взгляд, существует ключевая проблема в химической подготовке будущих инженеров. Квалифицированная подготовка бакалавров и специалистов химических направлений для отраслей топливно-энергетического комплекса (ТЭК) - необходимое условие развития государства. Несомненно, элементы химической грамотности, основы химической подготовки как начальной базы подготовки закладываются в общеобразовательной школе. Однако при этом следует отметить химическую безграмотность, проявление элементов особой хемофобии в современной школе, выстроенной с учетом таких тезисов, как «химия - это непонятно», «химия - это не актуально», «химия - это вредно», «химия - это опасно», «химию мне не надо». Современный ученик не профилирован на профессиональную деятельность в химической, нефтехимической, нефтегазоперерабатывающей промышленности. Здесь велика роль учителя химии, который раскрывает востребованность химических знаний для отраслей ТЭК российского государства, ориентирует на понимание того, что знания по химии раскрывают комплекс зависимостей, таких как «человек - профессия - химическое вещество», «химическое вещество - новый материал - профессиональная деятельность».

Обучаясь в вузе, студенты усваивают новые закономерности: химические основы фундаментальности представлений о мире; сочетание строения, состава, свойств химической системы; представления о вероятности, хаосе, порядке; передача энергии; структурные частицы; закономерности химических процессов с учетом дискретного и непрерывного, эволюции химических понятий и веществ. Полноценное усвоение знаний, их фундаментальность необходимы, но при этом бакалавр в стенах инженерного вуза, прежде всего, работает над собой, развивает свой интеллект, интеллектуальную культуру, которая обеспечит ему химическую грамотность и компетентность.

Совершенствование химической подготовки мы связываем с организацией процесса развития интеллектуальной культуры как определенной системы и личностного качества, позволяющего проводить анализ критериев, показателей, механизмов химико-технологического явления на основе мыслительных операций, востребованных для дальнейшего профессионального развития.

Цель исследования: совершенствование химической подготовки в школе и вузе с учетом применения приемов и методов развития интеллектуальной культуры.

\section{Материалы и методы исследования}

Разработка системы химической подготовки с учетом системообразующего принципа, ориентированного на развитие интеллектуальной культуры школьников и студентов - ключевая задача нашего исследования. Для достижения поставленной задачи использовались приоритетные мето- 
ды: теоретический, методологический анализ ведущих концепций, идей, проведение контент-анализа, выборка ведущих авторов по исследуемой проблеме, сравнительный, сопоставительный анализ. В ходе изучения педагогического опыта использовался метод классификации, аналогий. Эмпирические методы отражали сравнительный анализ анкет, бесед не только школьников, студентов, но и педагогов. Статистические методы проводились с учетом методов математического анализа.

\section{Результаты исследования и их обсуждение}

Научный дискурс понятия «интеллектуальная культура» показывает его многозначность и универсальность. Если говорить о данном понятии как о сложном феномене, то рассматривать его в рамках устоявшихся классических понятий психологии, педагогики надо начиная с интеллекта и общей культуры личности. Категория интеллект в рамках текстологии, альтернативных теорий, экспериментальной психологии обозначена М.А. Холодной как специфика организации умственного опыта человека с учетом компонентов (когнитивный, метакогнитивный, интенциональный опыт), обеспечивающих познавательную активность [2].

Если говорить о данном понятии и рассматривать его в рамках педагогического осмысления, то следует понимать такие ключевые позиции, как активность познания, проявление умственных способностей на практике, активность логических приемов (анализ, синтез, сравнение, причинноследственные связи). Философский аспект понятия интеллект связан с разумом, способностями души человека, постигающего суть вещей, явлений.

Категория культуры в педагогическом и профессиональном образовании многозначна. Научно-теоретический обзор позволил раскрыть понятие интеллектуальная культура как определенную часть общей культуры, включающей знаниевую систему (умственный кругозор) и систему умственных умений, обеспечивающих высокий уровень развития учащегося для анализа социально-культурных, социально-психологических, инженерных контекстов [3].

Для раскрытия теоретико-методологических основ интеллектуальной культуры были проанализированы труды Новосибирской научной школы философов в 1970-1990 гг. Так, профессор И.С. Ладенко, раскрывая проблемы интеллектуального развития общества в условиях научно-технического прогресса, делает акцент на необходимость и значимость исследований ключевых факторов развития интеллектуальной культуры в рамках глобальности современного мира. Ключевая позиция исследователя та, что интеллектуальная культура - основа общества нового типа [4]. Поэтому каждое общество борется за великие интеллектуальные умы, которые способны переходить, мигрировать из одной страны в другую, решая ключевые задачи страны.

Педагогическое сообщество раскрывает интеллектуальную культуру как индивидуально-личностное образование человека, совокупность проявления его когнитивных, деятельностных, личностных качеств в рамках решения многообразных задач.

Возникает вопрос: почему педагогическое, профессиональное сообщество все чаще обращается к данному понятию? Здесь уместно сделать акцент на ряд причин.

Во-первых, научные достижения многообразны в областях естественнонаучного плана, технологий, промышленности, для чего требуется новая типология мышления, уникальность общекультурных, общепрофессиональных, профессиональных (инженерных) компетенций. Реализация принципа конвергентности обосновывает включение новых направлений, построенных на ключевых основах (нано-, био-, инфо-, когнито-) техники и технологий. Это тот технологический уровень, который требует совершенствования учебной, производственной, научно-исследовательской деятельности в вузе и школе.

C другой стороны, выпускник школы и вуза не только понимает устройство материального мира, анализирует глобальные проблемы (климат, чистая вода, воздух, пища, энергия, окружающая среда и ее проблемы), но и ориентирован на познание, совершенствование своих качественных умственных характеристик.

Это значимо еще и потому, что будущий специалист, бакалавр, магистр уже в вузе ориентирован на изучение сертифицированных программ с учетом культурных, компетентных показателей, на основе интеграции научных, образовательных, производственных достижений.

Раскрыв основные позиции актуальности интеллектуальной культуры в социуме, жизнедеятельности, отметим ее ключевую роль в повышении качества химической подготовки современного выпускника. Сделаем некоторые пояснения: во-первых, показатели химической подготовки определяются интеллектуальным потенциалом самого человека, в соответствии с его умственными характеристиками, развитием интеллекта как своеобразных условий и результатов обученности, образованности; во- 
вторых, уровень химической подготовки связан с субъектной удовлетворенностью, развитием своих знаний, умений, качеств.

Одним из главных результатов химической подготовки студентов является профессиональная составляющая. Однако химическая подготовка в инженерных вузах оказывается краткосрочной, сжатой. Это значит, что большой объем материала приходится модулировать, чтобы за краткое время выдать объемную информацию. При этом у первокурсников нет интереса к химической подготовке из-за отсутствия химических знаний. Да и готовились они к единому государственному экзамену по физике, а не по химии. Данный парадокс проявляется повсеместно. У абитуриентов нет выбора при поступлении (химия или физика). А кто их научил развивать свою интеллектуальную культуру, научил навыкам, умениям, познанию?

Нами внедрена система химической подготовки, где системообразующим элементом является интеллектуальная культура, доказана поэтапность химической подготовки с учетом последовательного включения приемов, методов, содержательных блоков развития интеллектуальной культуры.

Культурологический блок строился с учетом достижения взаимосвязи химии и культуры; исторический блок раскрывал историю химических открытий; когнитивный блок делал акцент на отработку умственных приемов.

Среди выделенных критериев приоритетны: интеллектуальная компетентность (ИК), интеллектуальные умения, готовность к профессиональной деятельности. Интеллектуальная компетентность (ИК) совокупность знаний, умений, проявляемых в умственной деятельности [5]. Умения (интеллектуальные) - умения мыслить, развивают познавательные способности в химической подготовке. Готовность к профессиональной деятельности строится через компоненты рефлексии (оценка интеллектуальных ресурсов, внешняя позиция по отношению к своей подготовке и интеллектуальной культуре).

Методология химической подготовки определялась рядом подходов. Основа её мировоззренческая база химической подготовки для развития нравственных параметров и тех качеств, которые присущи лучшим представителям российской химической науки - это культурологический подход.

Практика реализации химической подготовки на основе приемов развития интеллектуальной культуры проводилась с использованием научно-исследовательской, деятельности, методов проектов, интерактивной деятельности.

Отслеживая уровень химической подготовки, мы учитывали результативность видов деятельности: деятельность на учебном занятии (задачи, химический эксперимент, синтез, практикум), научно-исследовательская деятельность (проект, доклад на конференции, научная статья, мини-открытие, патент). Проявление элементов культуры познания (время, ответственность, план, цель, приемы когнитивности, рефлексия). Проявление опыта коммуникаций строилось с учетом поведенческих характеристик (сотрудничество, общая, профессиональная культура). Система химической подготовки на основе развития интеллектуальной культуры внедрялась с 1 по 4 курс у бакалавров (направление «Химическая технология»). Качественные показатели химической подготовки учитывались и соотносились с учетом уровня развития интеллектуальной культуры (таблица).

Средние результаты выраженности уровней химической подготовки в контрольной группе (КГ) и экспериментальной группе (ЭГ)

\begin{tabular}{|c|c|c|c|c|c|c|c|}
\hline \multirow[t]{2}{*}{ Группы } & \multirow[t]{2}{*}{ Кол-во } & \multicolumn{2}{|c|}{ Низкий } & \multicolumn{2}{|c|}{ Средний } & \multicolumn{2}{|c|}{ Высокий } \\
\hline & & Кол-во & $\%$ & Кол-во & $\%$ & Кол-во & $\%$ \\
\hline \multicolumn{8}{|c|}{ Интеллектуальная компетентность } \\
\hline КГ & 22 & 8 & 36,3 & 11 & 50,0 & 3 & 13,7 \\
\hline$Э \Gamma$ & 24 & 2 & 8,3 & 12 & 50,0 & 10 & 41,7 \\
\hline \multicolumn{8}{|c|}{ Интеллектуальные умения } \\
\hline КГ & 22 & 10 & 45,5 & 9 & 41,0 & 3 & 13,5 \\
\hline ЭГ & 24 & 2 & 8,3 & 10 & 41,6 & 12 & 50,1 \\
\hline \multicolumn{8}{|c|}{ Готовность к профессиональной деятельности } \\
\hline КГ & 22 & 9 & 40,9 & 8 & 36,4 & 5 & 23,6 \\
\hline ЭГ & 24 & 3 & 12,5 & 9 & 37,5 & 12 & 44,2 \\
\hline \multicolumn{8}{|c|}{ Средние показатели } \\
\hline КГ & 22 & 9 & 40,9 & 9 & 40,9 & 4 & 18,2 \\
\hline$Э \Gamma$ & 24 & 2 & 8,3 & 10 & 41,6 & 12 & 50,1 \\
\hline
\end{tabular}


Методика анализа интеллектуальной компетентности (М.А. Холодная) строилась на основе экспертной оценки следующих качеств: химическая эрудиция, широта научно-технического кругозора. Результаты по показателю «Интеллектуальная компетентность»: высокий уровень - прирост в 3 раза; на среднем уровне значения равноценны между КГ и ЭГ; на низком уровне преобладают студенты контрольной группы $(36,3 \%)$.

Методика анализа интеллектуальных умений строилась на основе анализа по применению мыслительных приемов при решении химических задач (анализ, синтез, сравнение, обобщение, установление причинно-следственных связей). Результаты по показателю «Интеллектуальные умения»: высокий уровень - прирост в 3,7 раза; на среднем уровне разница значений между КГ и ЭГ отличается всего в 0,6 раза; на низком уровне оказалось $45,5 \%$ студентов контрольной группы.

Методика выявления готовности к профессиональной деятельности проводилась на основе анализа развития общекультурных, общепрофессиональных, профессиональных компетенций по разработанному тесту. В состав теста был включен ряд заданий, составленных ведущими инженерами промышленного предприятия по данному направлению. При этом учитывались и результаты научно-исследовательской, производственной, преддипломной практики. Результаты по показателю «Готовность к профессиональной деятельности»: высокий уровень - прирост в 1,8 раза; на среднем уровне разница значений между КГ и ЭГ составила 1,1 раза; на низком уровне оказались студенты контрольной группы (40,9\%).

Студенты ЭГ вышли на высокий уровень химической подготовки и развития интеллектуальной культуры в количестве $50,1 \%$. Однако $8,3 \%$ студентов из этой группы оказались на низком уровне. При опросе студентов ЭГ были выявлены причины, по которым они оказались на низком уровне: мотивационные (отсутствие интереса, нежелание заниматься наукой), профессиональные (поступил в вуз по желанию родителей, низкий кругозор, случайная профессия).

Химическая подготовка с учетом развития интеллектуальной культуры обучающихся в ЭГ показала достойные качественные результаты при выполнении производственной, преддипломной практики, защиты дипломных проектов. Все студенты экспериментальной группы выполняли выпускные квалификационные работы по темам промышленного предприятия, делали доклады по научно-исследовательской работе. Наблюдение за производственной деятельностью бакалавров показывает, что уже на первых этапах работы они активны в науке, производстве, социокультурной жизни предприятия [6].

\section{Заключение}

Таким образом, высокий уровень химической подготовки необходимо связывать с процессом развития интеллектуальной культуры, для получения качественных результатов через систему ведущих приемов, гарантирующих результат, компетентность будущих бакалавров, специалистов.

\section{Список литературы}

1. Митрофанов Д.В. Особенности интеллектуальной культуры студентов // Вестник Тамбовского университета. Серия Гуманитарные науки. 2016. Т. 21. № 10 (162). С. 14 18. DOI: 10.20310/1810-0201-2016-21-10(162)-14-19.

2. Холодная М.А. Психология интеллекта. Парадоксы исследования: учебное пособие для бакалавриата и магистратуры. М.: Издательство «Юрайт», 2019. 334 с.

3. Адилова В.Х. Историческая ретроспектива становления понятия «культура интеллектуального труда» // Научно-практический журнал «Гуманизация образования». 2016. № 6. С. $68-73$.

4. Ладенко И.С. Проблемы интеллектуального развития общества в условиях научно-технического прогресса: Концепция комплексной программы научных исследований. Новосибирск: Б.И., 1990. 50 с.

5. Юсупова А.Ж. Интеллектуальная компетентность личности: сущность и возможности ее становления в системе образования// Вестник КРСУ. 2018. Т. 18. № 1. C. 212-215.

6. Egorova G.I., Loseva N.I., Ivanova O.A., Chubarova B.M., Demidova O.M. Intellectics fundamentals in a professional activity of a future bachelor. Advances in intelligent systems and computing. 2019. vol. 907. P. 45-52. DOI: 10.1007/ 978-3-030-11473-2 5 . 